\title{
An Abstract: Consumer's Acceptance of Food Innovations: Effects on Product Perception and Consumer Behavior
}

\author{
Levke Albertsen, Klaus-Peter Wiedmann, Evmorfia Karampournioti, \\ and Sascha Langner
}

\begin{abstract}
The relentless progress in research and the resulting new food technologies enable a variety of innovations in the food sector. However, in general, consumers are often highly skeptical about new products and perceive great (consumption) risks when that innovative product has been produced and created by a more or less unfamiliar technology. An increasing mistrust of consumers toward the food chain led to a decreasing acceptance of regular and newly developed products. However, consumer acceptance is crucial to the development of successful food products. Adding the increased consumer interest in food production technology, consumers' overall attitudes toward new food technologies should be taken into account in order to be successful in the market. Against that background, the present study aims to analyze in detail the factors that affect consumers' acceptance of innovative food products. Specifically, a new multifaceted model of consumers' acceptance of innovative food products is developed and empirically tested considering the influence on product image and buying intention as selected product performance outcomes. As investigation object, an innovative flavor enhancer was used, which improves consumers' health by strengthening the flavor of salt and thus helping to reduce salt levels in food.
\end{abstract}

L. Albertsen $(\bowtie) \cdot$ K.-P. Wiedmann $\cdot$ E. Karampournioti $\cdot$ S. Langner

Leibniz University of Hannover, Hannover, Germany

e-mail: albertsen@m2.uni-hannover.de; wiedmann@m2.uni-hannover.de;

karampournioti@m2.uni-hannover.de; langner@m2.uni-hannover.de 